\title{
Northern South China Sea Surface Circulation and its Variability Derived by Combining Satellite Altimetry and Surface Drifter Data
}

\author{
N. Peter Benny *, K. Rayaroth Mridula, Mohd Razali Mahmud, Sahrum Ses, and Kamaludin Mohd Omar \\ Department of Geoinformation, University of Technology Malaysia, Malaysia
}

Received 31 December 2013, revised 27 June 2014, accepted 2 December 2014

\begin{abstract}
The present study analyses the mean and seasonal mesoscale surface circulation of the Northern South China Sea (NSCS) and determines the influence of El Niño/Southern Oscillation (ENSO). High resolution Eulerian velocity field is derived by combining the available satellite tracked surface drifter data with satellite altimetry during 1993 - 2012. The wind driven current is computed employing the weekly ocean surface mean wind fields derived from the scatterometers on board ERS $1 / 2$, QuikSCAT and ASCAT. The derived mean velocity field exhibits strong boundary currents and broad zonal flow across NSCS. The anomalous field is quite strong in the southern part and the Seasonal circulation clearly depicts the monsoonal forcing. Eddy Kinetic Energy (EKE) distribution and its spatial and temporal structures are determined employing Empirical Orthogonal Function (EOF) analysis. The ENSO influence on NSCS surface circulation has been analyzed using monthly absolute geostrophic velocity fields during 1996 - 1999.
\end{abstract}

Key words: South China Sea, Satellite altimetry, Kuroshio Current, Surface drifter, Surface circulation

Citation: Benny, N.P., K.R.Mridula, M.R. Mahmud, S. Ses, and K. M. Omar, 2015: Northern South China Sea surface circulation and its variability derived by combining satellite altimetry and surface drifter data. Terr. Atmos. Ocean. Sci., 26, 193-203, doi: 10.3319/TAO.2014.12.02.04(EOSI)

\section{INTRODUCTION}

The South China Sea (SCS) has received much attention in recent years as it is seriously influencing the climate and ecosystem of Southeast Asian countries. The SCS is the largest marginal sea in Southeast Asia. It is a semi-enclosed tropical sea that lies between the Asian Continent and $\mathrm{Pa}$ cific Ocean. The northern part of the SCS is well connected to the western Pacific through the Luzon Strait and to the East China Sea through the Taiwan Strait.

Preliminary studies by Dale (1956) and Wyrtki (1961) proposed seasonal varying monsoon SCS circulation with cyclonic and anticyclonic flows in winter and summer respectively. Later, Xu et al. (1982) identified the role of meso-scale eddies in SCS circulation. The SCS surface circulation is driven by monsoon winds but, significantly modified by Kuroshio Current intrusion from the western Pacific. Fresh water input in the western and northern parts of the basin also results in large seasonal variation in surface layer stratification and hence the dynamics.

In the Northern South China Sea (NSCS) the circula-

\footnotetext{
* Corresponding author

E-mail: bennyneettumkara@utm.my
}

tion is greatly influenced by the Kuroshio intrusion (Shaw and Chao 1994; Qu 2000) and significant mesoscale eddy activity (Yuan et al. 2006). The Kuroshio flows northward along the east coast of Luzon and intrudes slightly and exchanges Western Pacific Surface Water (WPSW) into the SCS via the Luzon Strait and again continues northward along the east coast of Taiwan. Fang et al. (1991) estimated an average northward transport of $2 \mathrm{~Sv}$ in the Taiwan Strait and 2.2 Sv southward through the Sulu Sea (Qu et al. 2000). Thus, a net transport of 4.2 - $5 \mathrm{~Sv}$ WPSW enters into the SCS through the Luzon Strait (Su 2004). Earlier studies (Chu 1972; Nitani 1972) suggested the Kuroshio component could loop around inside the SCS or even intrude as a direct current (SCSIO 1985). Recent observational studies (Xu et al. 1996; Wu et al. 1998; Liu et al. 2001a) did not support either of the suggested flow patterns. Numerical modeling (Metzger and Hurlburt 1996) predicted a loop current and a branch current both from the Kuroshio, inside the SCS. Pichevin and Nof (1997) suggested the only possibility for part of the Kuroshio water to enter through the Strait is via mesoscale eddies and observed such an eddy from observations during the summer of 1994 ( $\mathrm{Li}$ et al. 1998). Wang and 
Chern (1997) suggested sub-mesoscale processes also for the influx of Kuroshio to the SCS.

Xu et al. (1982) derived the flow pattern from the dynamic topography using historical oceanographic data and found that the monsoon circulation pattern extends down to $500 \mathrm{~m}$ depths. Further studies (Ho et al. 2000; Hwang and Chen 2000; Kuo et al. 2000; Liu et al. 2001b) using satellite observations also supported the earlier results from hydrographic observations.

Significant mesoscale variability is found in the SCS from hydrographic observations (Chu et al. 1998; Kuo et al. 2000; Ho et al. 2004) and strong variability north of $10^{\circ} \mathrm{N}$ from altimetry (Wang et al. 2000) is also confirmed from airborne XBT surveys (Chu et al. 1998). The generation mechanism for mesoscale eddies may be vorticity advection through the Kuroshio (Su 1998). Different studies (Liu and Su 1992; Qu et al. 2000; Cai et al. 2002) discusses the various generating mechanisms of the mesoscale eddies in the SCS.

A detailed review on SCS circulation is given by $\mathrm{Su}$ (2004) and the advances in understanding the SCS western boundary current is summed up in Fang et al. (2012). Recent studies (Hu et al. 2011; Jiang et al. 2011; Gao et al. 2013) have further enhanced our understanding of SCS circulation and variability.

However, as there is no systematic observational network available for the SCS, the details on scales of motion and its variability still lacking. The present study has two important goals. First it presents a new high resolution $\left(1 / 3^{\circ}\right.$ latitude $\times$ $1 / 3^{\circ}$ longitude) mean surface velocity field data for NSCS by combining satellite altimetry and surface drifter observations. Second, this paper determines the seasonal and inter-annual variability of surface circulation and influences of ENSO (El Niño/Southern Oscillation) on the flow pattern.

The rest of this paper is organized as follows. Section 2 describes the data used and the methodology followed. Section 3 presents the NCSC surface circulation which includes mean, seasonal and inter-annual. Section 4 examines the NCSC mesoscale variability. The derived conclusions are presented in section 5 .

\section{DATA AND METHOD}

\subsection{Data Used}

Satellite tracked surface drifter data, satellite altimetry and ocean surface wind data were used in this study. The surface drifter data used in this study comes from the Global Drifter Program (Surface Velocity Program); with the freely drifting buoy positions located using the ARGOS satellite system. The surface buoys are attached to drogues centred at $15 \mathrm{~m}$ depth. The data used were quality controlled and optimally interpolated to uniform six-hour interval trajectories using the drifters' position data. This data set is compiled and maintained by the Drifter Data Centre at the Atlantic Oceanographic and Meteorological Laboratory of the National Oceanic and Atmospheric Administration, USA (http://www.aoml.noaa.gov/). Based on the drifter observations availability (Fig. 1) the study area is limited between $105-123^{\circ} \mathrm{E}$ and $10-26^{\circ} \mathrm{N}$.

The satellite altimeter data used in this study were delayed mode, weekly Maps of Sea Level Anomaly (MSLA) produced by the Collect Localisation Satellites (CLS), France (http://www.aviso.altimetry.fr/). The MSLA were obtained by merging JASON/TOPEX/POSEIDON and European Remote Sensing Satellites ERS/Envisat data using optimum interpolation. The ocean surface mean wind fields derived from the scatterometers on board ERS 1/2, QuikSCAT and ASCAT generated by CREST, France (http:// www.cersat.ifremer.fr/) have also been used to compute the wind-driven component from the drifter velocity.

\subsection{Method}

The method introduced by Uchida and Imawaki (2003) was employed in this study, in which surface drifter and
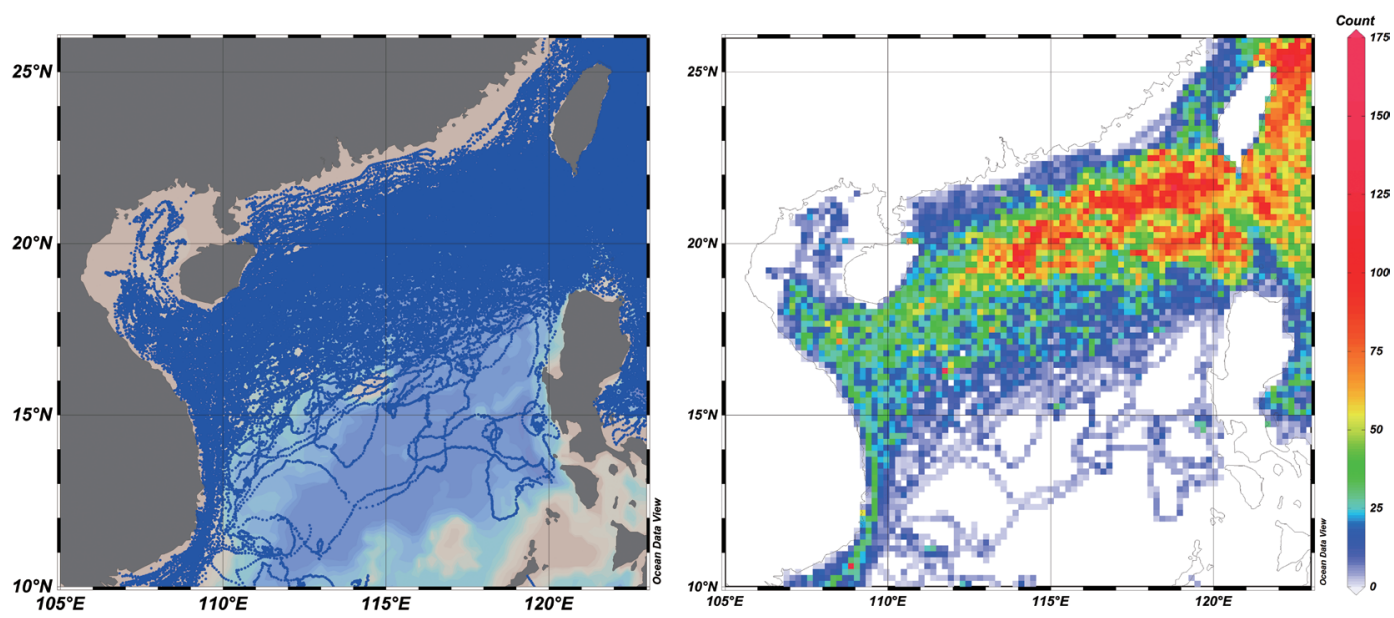

Fig. 1. Left panel: drifter tracks in the Northern South China Sea (NSCS) (1993 - 2012); right panel: data density statistics. 
altimeter data are combined to estimate the mean surface velocity.

At a location $\mathrm{x}$ and time $\mathrm{t}$, the instantaneous geostrophic velocity $\operatorname{Vg}(x, t)$ can be written as

$\operatorname{Vg}(x, t)=\operatorname{Vmg}(x)+V^{\prime}(x, t)$

where, $\operatorname{Vmg}(\mathrm{x})$ is the mean geostrophic velocity, $\operatorname{Vg}^{\prime}(\mathrm{x}, \mathrm{t})$ is the geostrophic velocity anomaly.

The instantaneous geostrophic velocity can be derived from the drifter observations and the altimeter sea level anomalies provide the anomaly field. Hence, the mean velocity is calculated by subtracting the altimeter derived geostrophic velocity anomaly from the drifter-derived geostrophic velocity measured at the same time and location. This method estimates nearly unbiased Eulerian mean velocities which are free from the drifter sampling tendency. Thus, the unknown mean velocity can be estimated for the grid box where a drifter had passed. The average of the calculated mean velocities in each grid; $\langle\mathrm{Vmg}(\mathrm{x})\rangle$ gives a more accurate estimate by reducing the estimation error.

The drifter trajectories were low-pass filtered using a 30 -hour running mean to remove high frequency fluctuations. The drifter data was then been gridded into $1 / 3^{\circ}$ latitude $\times 1 / 3^{\circ}$ longitude altimeter observation boxes. The surface velocity was estimated from the drifter position data in each grid (Fig. 2). The wind-produced slip was corrected by employing the relation given by Niiler and Paduan (1995). An additional correction was made for drifters that had lost their drogues during their traverse, using the empirical relation given by Pazan and Niiler (2001). The Ekman velocity was estimated employing the Ralph and Niiler (1999) model. The geostrophic velocity component was separated from the drifter velocity by subtracting the Ekman component.

The geostrophic velocity anomaly components were computed from altimeter sea level anomaly data using the conventional geostrophic relation.

$$
\begin{aligned}
& u^{\prime}=-\frac{g}{f} \frac{\partial h}{\partial y} \\
& v^{\prime}=\frac{g}{f} \frac{\partial h}{\partial x}
\end{aligned}
$$

The time series maps of instantaneous geostrophic velocity field were prepared in combination with the time series MSLA and the estimated mean velocity field.

\section{SURFACE CIRCULATION}

\subsection{Mean Velocity Field}

The estimated Eulerian mean velocity field of NSCS exhibits strong currents in the eastern and western parts whereas weak flows prevail in the southern and northern parts (Fig. 3). The Kuroshio Current intrusion from the western Pacific with speeds around $1 \mathrm{~m} \mathrm{~s}^{-1}$ is clearly visible in the Luzon Strait and it crosses the NSCS with low speeds as a zonal broad westward flow. The major part of the flow turns southward towards the Vietnam Coast and further intensified with speeds up to $1 \mathrm{~m} \mathrm{~s}^{-1}$. A minor part of the zonal current also enters the Tonkin gulf around Hainan Island. In the northwest region $\left(21-23^{\circ} \mathrm{N}\right)$ along the south coast of China strong westward flow with speed around $0.6 \mathrm{~m} \mathrm{~s}^{-1}$ prevails. The mean field shows strong northward flow on the eastern side and southward flow in the western side of the Taiwan Strait. A weak outflow to the Pacific through the northern part of the Luzon Strait is also visible in the mean field. The strong northward flow from the northwestern coast of the Philippines joins with the Kuroshio intrusion and contributes to the zonal westward flow. In general, the flow pattern shows a cyclonic circulation in the NSCS.

The altimeter derived velocity anomaly average (Fig. 4) reveals the variability occurring in the flow field. The maximum anomaly is found in the southwestern part off the Vietnam Coast with $0.5 \mathrm{~m} \mathrm{~s}^{-1}$ towards south. The anomaly field is prominent between $15-18^{\circ} \mathrm{N}$ in the zonal band from Vietnam to the Philippines. Significant deviations are also noticed around and northeast of Hainan Island and in the Taiwan Strait. Interestingly, the anomaly field is very weak in the Luzon Strait where strong flow is present in the mean field.

The average velocity field was obtained by combining all the drifter data is given in Fig 5. A maximum speed of $1.25 \mathrm{~m} \mathrm{~s}^{-1}$ is found along the eastern boundary of Vietnam and the flow is quite strong and broad even from the Coast of Hainan Island. In the Luzon Strait the Kuroshio component speed is around $1 \mathrm{~m} \mathrm{~s}^{-1}$ and in the central NSCS the broad zonal flow is quite strong. Northward flow prevails in the eastern side and return flow in the western part along the Taiwan Strait.

The mean circulation pattern is obviously illustrating

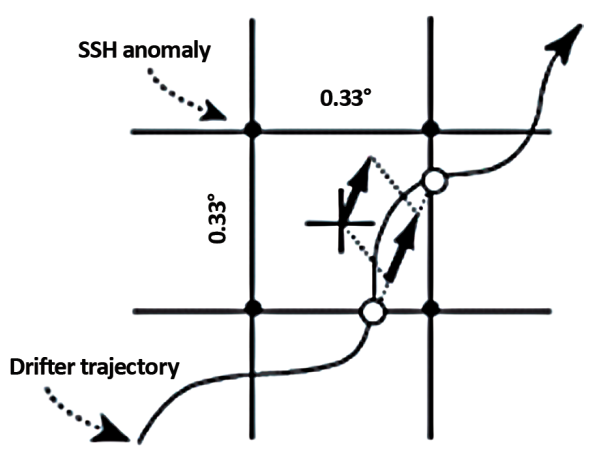

Fig. 2. Schematic diagram showing the method used to calculate velocity from a low pass-filtered drifter trajectory. The velocity for a $1 / 3^{\circ}$ latitude $\times 1 / 3^{\circ}$ longitude box defined by grid points of the altimeter data is calculated from two positions (open circles) and times where and when a drifter comes in and goes out the box. 


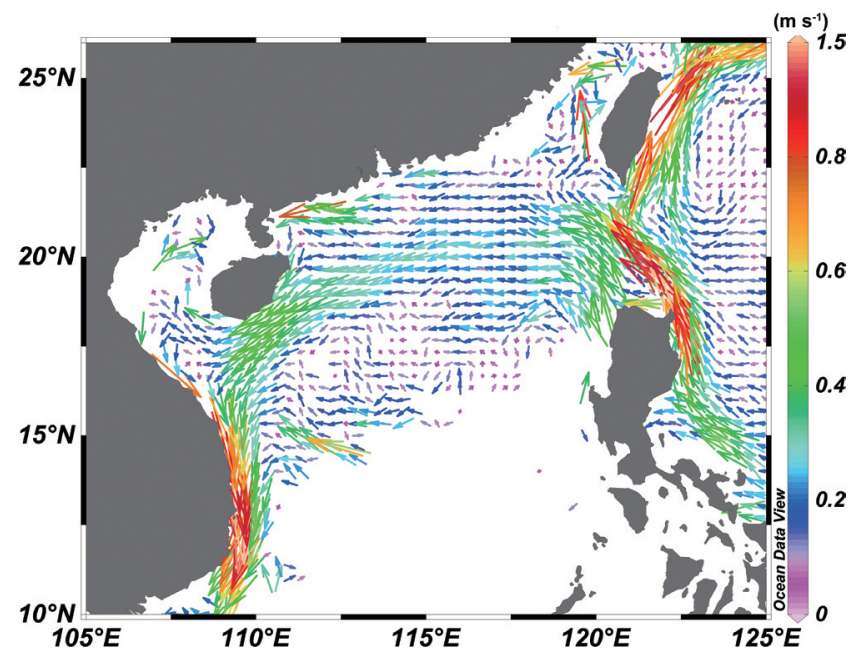

Fig. 3. Mean surface velocity field $[\operatorname{Vmg}(x)]$ of NSCS derived by combining satellite altimetry and surface drifter observations.

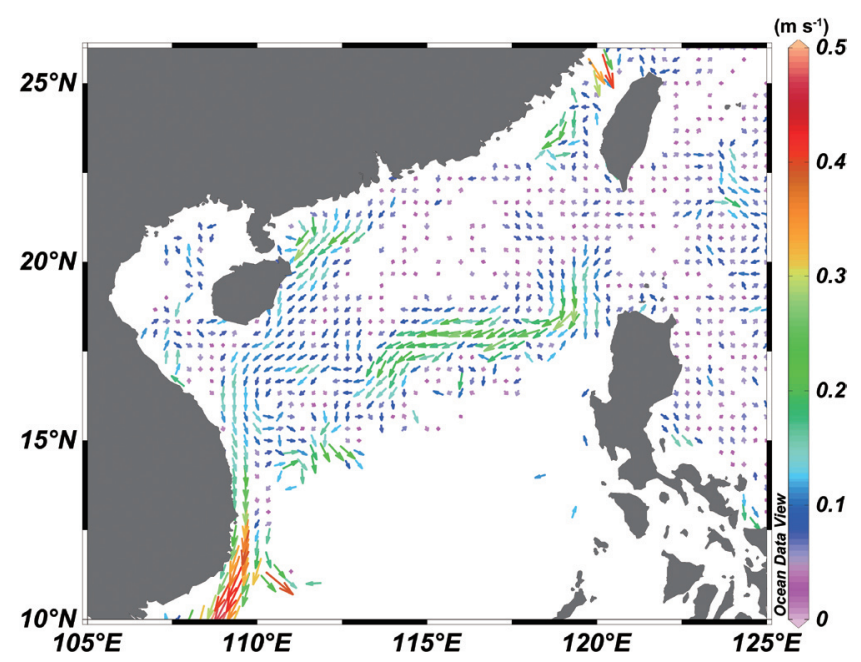

Fig. 4.Map of simple averages of geostrophic velocity anomaly [ $\left.\mathrm{Vg}^{\prime}(\mathrm{x}, \mathrm{t})\right]$ computed from altimeter data used for estimation of mean field.

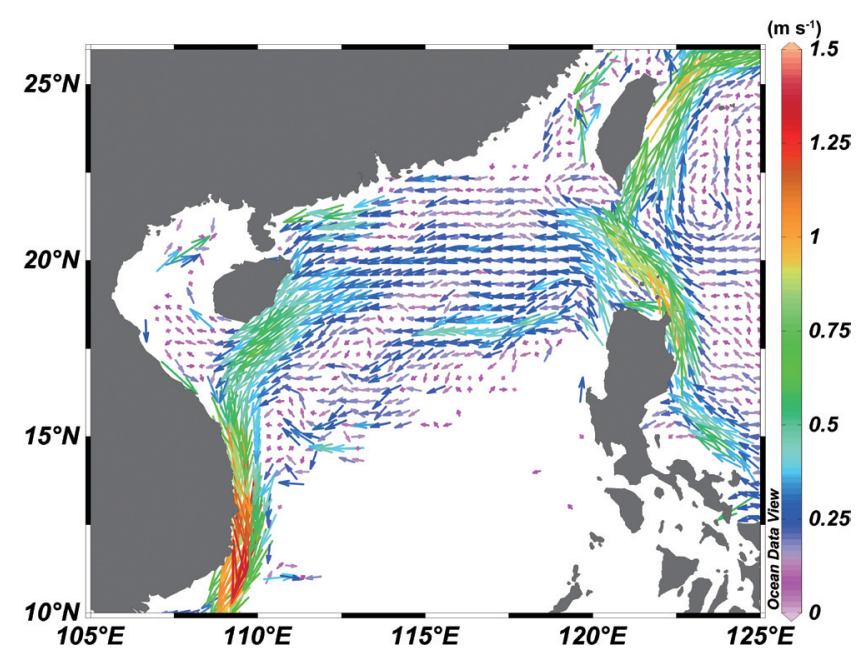

Fig. 5. Map of simple averages of instantaneous geostrophic velocity $[\operatorname{Vg}(\mathrm{x}, \mathrm{t})]$ estimated from drifter data used for estimation of mean field. cyclonic gyral circulation (Wyrtki 1961) in NSCS. Western boundary current is the strongest in the mean field and the maximum speed is at around $12^{\circ} \mathrm{N}$. The north eastward surface current, named SCS Warm Current (Guan 1978) is not visible in the mean field. Northward flow is prominent on the eastern side of the Taiwan Strait however, weak southward flow occurs on the western side. Fang et al. (1991) reported the net mass transport in the Taiwan Strait is towards the north throughout the year. The Kuroshio Current intrusion with speeds up to $1 \mathrm{~m} \mathrm{~s}^{-1}$ is found at the Luzon Strait.

\subsection{Comparison with In-Situ Acoustic Doppler Current Profiler Observations}

We computed the instantaneous weekly velocity field using the time series altimeter-derived velocity anomaly field and the estimated mean velocity field and compared it with the available in-situ velocities measured by the shipboard Acoustic Doppler Current Profiler (ADCP) obtained from WOCE cruises (WOCE Global Data version 3.0) of R/V FIRST JUPITER (cruise id 229, 230) during April - May 1997 to validate the estimated velocity. The depth of ADCP data used is $70 \mathrm{~m}$ and we assumed that it represents the near surface geostrophic current. One hundred and twenty-three ADCP observations were obtained for comparison in the study region. The instantaneous velocity estimated in this study is in good agreement with the ADCP derived velocities (Fig. 6). The correlation co-efficient obtained for zonalcomponent and meridional-component velocities are 0.83 and 0.81 , respectively.

\subsection{Monthly Average Velocity Field}

Monthly average geostrophic velocity filed has been constructed using the sea level anomaly time series data (1993 - 2012) and the estimated mean field. In order to understand the seasonal circulation pattern the velocity fields of January, April, July, and October are shown in Fig. 7.

Strong circulation prevails over major part of the NSCS in January (winter monsoon), with maximum current speeds $\left(1.25 \mathrm{~m} \mathrm{~s}^{-1}\right)$ around $12^{\circ} \mathrm{N}$ along the Vietnam Coast. Significant flows are also found in the Luzon Strait, west of the Philippines, along the eastern coast of China and Hainan Island. The zonal flow across the NSCS is strong and broad. A cyclonic eddy is found off the western Philippines between $16-18^{\circ} \mathrm{N}$ and an anticyclonic eddy is also visible in the Gulf of Tonkin.

The circulation weakens in April (inter-monsoon) compared to January as the north east monsoon wind is weakened. Along the western boundary the maximum current speed is reduced to $0.7 \mathrm{~m} \mathrm{~s}^{-1}$. In the Luzon Strait the Kuroshio component maintains the same magnitude as in January but the zonal flow across the NSCS becomes narrow and weak. The cyclonic and anticyclonic eddies noticed 
in January are quite weakened.

In July (summer monsoon) the circulation is further weakened and northward flow is observed in southwestern part. The western boundary current is much diffused and no organized pattern is found. The Kuroshio intrusion is still the same as in earlier months and continues northward through the Taiwan Strait.

Since the monsoon winds are changed in October (inter-monsoon) the surface circulation also responds with conspicuous changes. The western boundary current is very prominent and the speed reaches $1.3 \mathrm{~m} \mathrm{~s}^{-1}$ in the southwestern part. Zonal flow is also strengthened on the northern side and cyclonic and anticyclonic eddies are reappeared.

The seasonal circulation features of the NSCS confirm the monsoonal forcing and the Kuroshio Current intrusion. The Kuroshio component feeds the zonal cross basin flow in the winter monsoon and supports the northward flow along the Taiwan Strait. The seasonal circulation has different significant characteristics and the winter circulation is more active compared to the summer. Wyrtki (1961) proposed that the seasonal variation characteristic of SCS circulation is related to the East Asian Monsoon. Guo et al. (2006) found that the SCS seasonal variation is asymmetrical and the variation is stronger in winter than in summer.

\subsection{Circulation and ENSO}

The absolute geostrophic velocity fields of January, April, July, and October during 1996-1999 are compared to determine the ENSO influence on NSCS surface circulation (Fig. 8). According to the multivariate ENSO index 1996 is more or less a normal year whereas, strong El Niño
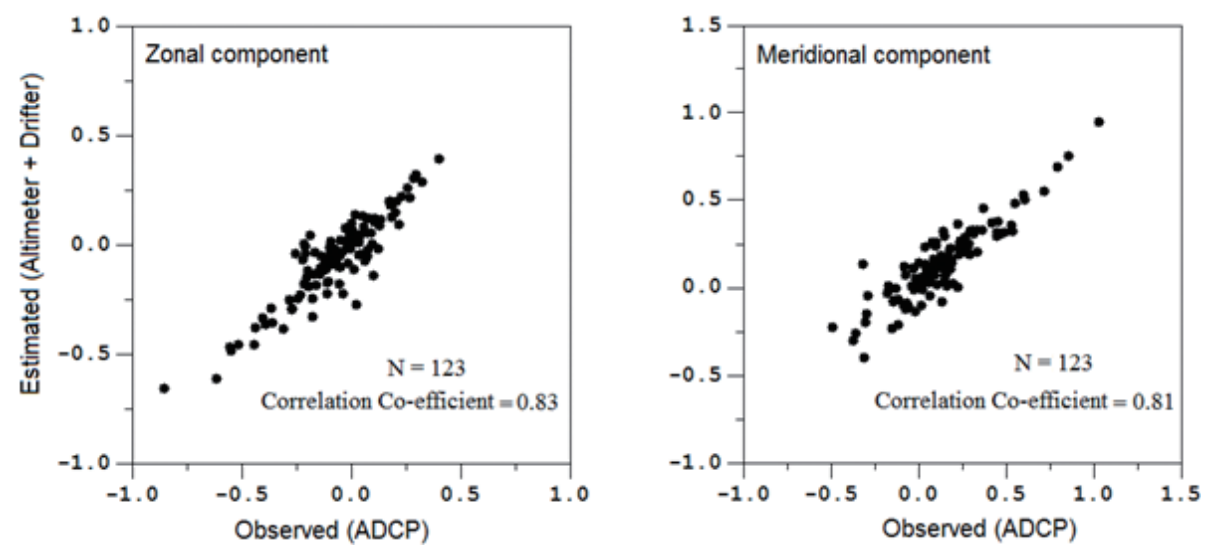

Fig. 6. Scatter plot of estimated instantaneous surface velocity components (ordinate) against observed ADCP-surface velocity components (abscissa).

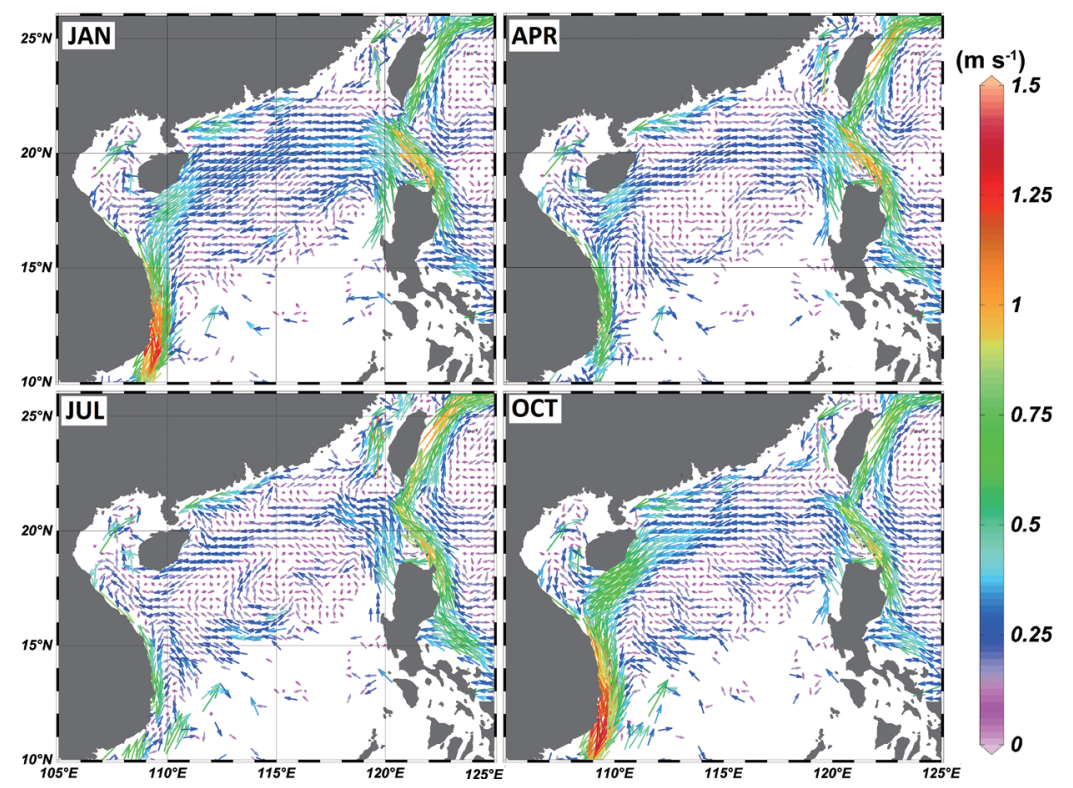

Fig. 7. Maps of monthly average absolute velocity field for January, April, July, and October. 


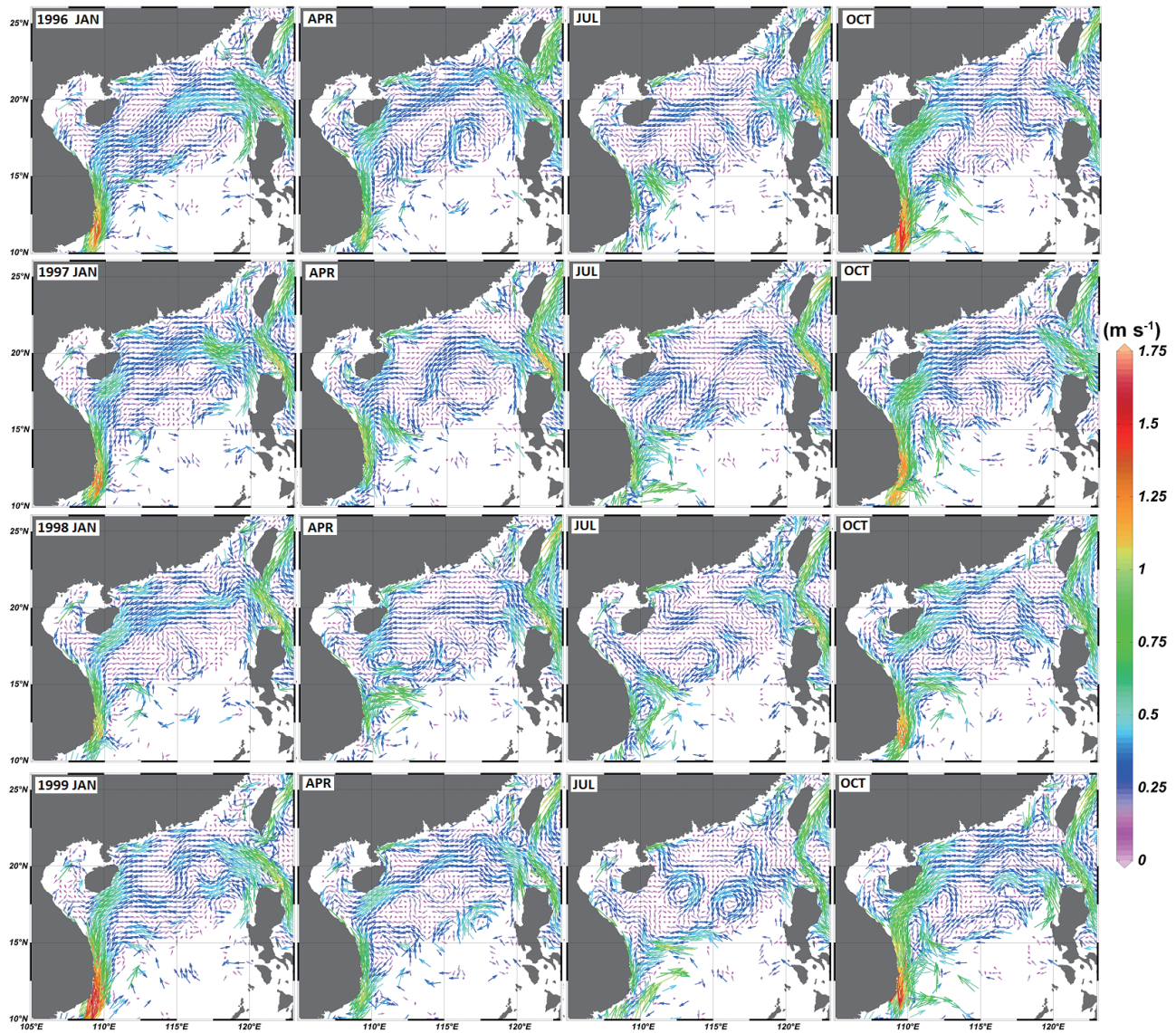

Fig. 8. Maps of monthly average absolute velocity field for January, April, July, and October of 1996, 1997, 1998, and 1999.

occurred during July 1997 to July 1998 and August 1998 to December 1999 La Nina condition prevails. We compared the circulation focusing on the zonal flow (Central region) and western boundary and eastern boundary regions.

\subsubsection{Central Region}

In January active circulation prevails in the NSCS with broad zonal flow in the central region in all the years except in 1998. In 1996 the zonal flow was comprised of three current branches; the northern branch supported by the southward flow from the Taiwan Strait and the middle branch, the strongest and broadest branch contributed mainly by the Kuroshio component through the Luzon Strait. The southern limb is formed by the cyclonic flow from the western side of Luzon. In 1997 the zonal flow was slightly weak and the cores were faintly visible. The southern core was absent in 1998 but visible in 1999, embedded with eddies and meanders. Another significant feature found is that the zonal flow shifted more toward lower latitudes on the western side in 1996 and reached southwest of Hainan Island.

In April the northeast monsoon winds weakened and the surface circulation became dull. The flow patterns in 1996 and 1999 exhibited the middle branch zonal flow from the Luzon Strait to Hainan Island. However, in 1997 and 1998 the zonal flow was not continuous and was embedded with meanders. The zonal flow exhibited speed less than $0.25 \mathrm{~m} \mathrm{~s}^{-1}$ in the central NSCS and showed weak circulation in 1998 compared to other years.

The flow patterns in July during 1996 - 1999 illustrate significant El Niño influences. Overall, a weak circulation occurred in July and the zonal flow was more or less continuous from the Luzon Strait to Hainan Island only in 1996 and the speed was less than $0.4 \mathrm{~m} \mathrm{~s}^{-1}$.

In October strong and broad Kuroshio intrusion was found in 1997 compared to other years and formed a wellorganized zonal flow from the Luzon Strait to the Coast of Hainan Island. In 1998 the Kuroshio intrusion was again weakened and hence also the zonal flow.

\subsubsection{Western Boundary Region}

In January the western boundary current was slightly weak in 1997 compared to 1996. In 1998 the El Niño condition prevailed and the southward western boundary current weakened further with maximum speed is less than $1 \mathrm{~m} \mathrm{~s}^{-1}$. Conspicuous changes were found in the western boundary in 1999 (during the La Nina), where intense flow occurred 
from the Hainan Coast and the speed exceeded $1.5 \mathrm{~m} \mathrm{~s}^{-1}$ off Vietnam.

In April some significant changes were evident in the western boundary current. The southward flow was well organized in 1996 with a maximum speed of $1 \mathrm{~m} \mathrm{~s}^{-1}$ is at $12^{\circ} \mathrm{N}$. The current was still stronger $\left(1 \mathrm{~m} \mathrm{~s}^{-1}\right)$ in 1997 but the maximum speed location shifted more to the north at around $15^{\circ} \mathrm{N}$. A strong cyclonic eddy also formed near the coast in 1997. Remarkably, the western boundary flow was much weakened in 1998 with no organized flow pattern found. Instead strong cyclonic and anti-cyclonic eddies existed in the region. By 1999 the western boundary current was again back to normal patterns as in 1996 with speeds up to $1 \mathrm{~m} \mathrm{~s}^{-1}$. A clockwise circulation around the Hainan Coast was present in the western NSCS in all years except 1998.

In July along the east coast of Hainan Island southwestward flow exists only in 1996 and 1997, which is heading towards the Vietnam coast at speeds up to $1 \mathrm{~m} \mathrm{~s}^{-1}$ at $12^{\circ} \mathrm{N}$. In 1998 a cyclonic eddy was formed near the Vietnam Coast between $12-15^{\circ} \mathrm{N}$ and northwestward flow was prominent between $15-20^{\circ} \mathrm{N}$ (up to the southwest coast of Hainan Island). In 1999 a narrow southward coastal current was visible off Vietnam with strong northeastward flow appearing offshore between $12-15^{\circ} \mathrm{N}$ and weak northwestward flow prevailing between $15-20^{\circ} \mathrm{N}$.

In October 1996 the western boundary current is strong (about $1 \mathrm{~m} \mathrm{~s}^{-1}$ ) even from the Hainan Coast and attains maximum speed at $12^{\circ} \mathrm{N}\left(1.5 \mathrm{~m} \mathrm{~s}^{-1}\right)$. However, in 1997 and 1998 the western boundary current was weaker than in 1996 and the maximum speed was up to $1.25 \mathrm{~m} \mathrm{~s}^{-1}$. In 1999 the flow pattern was again similar to that in 1996 with the western boundary current strengthened with a maximum speed of $1.5 \mathrm{~m} \mathrm{~s}^{-1}$ at around $12^{\circ} \mathrm{N}$.

\subsubsection{Eastern Boundary Region}

In January 1996 and 1999 the Kuroshio intrusion into the SCS is clearly visible and part of it is recirculated into the Pacific at the northern end of the strait. A slight increase in Kuroshio Current speed is found in 1998 compared to other years and a major part of the intruded Kuroshio waters continued northward along the Taiwan Strait in 1998 with no return flow into the Pacific through the northern part of the Strait as in 1996 and 1999.

In April 1997 and 1998 the Kuroshio Current is faster compared to the other two years and a major part of the Kuroshio Current intruded through the Luzon Strait, feeding the northward flow. Significant northward flow strengthening occurred along the west coast of Taiwan in 1998. Moreover, the strong anti-cyclonic eddy present southwest of Taiwan during 1996 and 1999 was not visible in 1997 and 1998.

Strong northward flow was found in the Taiwan Strait in July except in 1997. Near the Luzon Strait region eddy circulation is dominant in 1996 but, well organized flow in 1997 and embedded with meanders in 1998 and 1999. The Kuroshio Current is narrow but with higher speeds in 1997 and 1998, while it is broad in 1996 and weak and narrow in 1999.

The northward flow in the Taiwan Strait was replaced with southward flow in October 1997. A broad strong southwestward flow occurred from the Taiwan Strait along the southwest coast of China, merging with zonal flow near Hainan Island in 1998.

Inter-annual NSCS surface circulation reveals the influence of ENSO in the zonal flow, western boundary and eastern boundary regions. The zonal flow is weakened in El Niño periods as major part of the intruded Kuroshio waters continuing northward along the Taiwan Strait. The southwest wind strengthens in summer during El Niño and is also retarding the zonal flow. Earlier studies reported weaker surface circulation in the SCS during 1982 - 1983 (Chao et al. 1996) and 1992 - 1995 El Niño periods (Wu et al. 1998). Wang et al. (2006) found that when El Niño matures in the Pacific in winter the SCS shows anomalous decent motion and weakening of the winter northeast monsoon.

The Kuroshio Current seems to be narrow and faster during El Niño periods and is weakened in La Nina periods. The northward flow through the Taiwan Strait is diminished during El Niño (July 1997) as the Kuroshio intrusion is weak.

Significant inter-annual variations in flow pattern are found in the western boundary. During La Nina periods the current is stronger than in normal years and in El Niño periods the western boundary flow is weak. In summer cyclonic eddy circulation dominates off the Vietnam Coast during El Niño. Guo et al. (2006) suggested prominent surface circulation variations due to El Niño events and found a series of mesoscale eddies in the western SCS. The climatic anomalies propagating from the Pacific Ocean into the western SCS through the Luzon Strait cause current variations in the western boundary. Previous studies (Wang et al. 1999; Wang et al. 2003; Qu et al. 2005) detected Pacific Rossby wave intrusion into the SCS with strong El Niño signals.

\section{MESOSCALE VARIABILITY}

The mesoscale variability of NSCS was examined in detail by estimating the Eddy Kinetic Energy (EKE) using the velocity anomalies $\left[1 / 2\left(u^{\prime 2}+v^{\prime 2}\right)\right]$. Employing Empirical Orthogonal Function (EOF) analysis the spatial structure and temporal modes of EKE variability are analyzed.

\subsection{Mean EKE}

The mean EKE is estimated using monthly velocity anomalies during the period 1993 - 2008 (Fig. 9). The EKE ranges from $0-0.12 \mathrm{~m}^{2} \mathrm{~s}^{-2}$ in the NSCS. Maximum EKE is found east of Vietnam between $10-12^{\circ} \mathrm{N}$ and minimum in northern and southern parts of NSCS. The Northern part of the Luzon Strait, Taiwan Strait and west of Hainan Island 
also exhibit comparatively high EKE.

The variation in seasonally averaged EKE over the study region during the period 1993 - 2008 is shown in Fig. 10. The EKE distribution shows intra-annual and interannual oscillations from climatic anomalies. During 1993 1996 large EKE oscillations were found $\left(0.01-0.03 \mathrm{~m}^{2} \mathrm{~s}^{-2}\right)$. However, in the period 1997 - 1998 the EKE shows minimum range of $0.015-0.02 \mathrm{~m}^{2} \mathrm{~s}^{-2}$ and this corresponds to the El Niño event. Again, the minimum EKE is observed during 2004 - 2005, also an El Niño period. Conversely, during 1999 - 2000, large EKE oscillations occurred, which correspond to the strong La Nina event. Interestingly, the EKE illustrates a decreasing trend in the NSCS during the 1993 - 2008 period.

\subsection{EOF Analysis}

The first three EOF modes contribute about $52 \%$ of the EKE variability in the NSCS. The spatial structure of EOF mode 1 which explains $30 \%$ of the variability shows higher values east of Vietnam between $10-15^{\circ} \mathrm{N}$ (Fig. 11). Significant variability also exists in the Taiwan Strait and southwest of Hainan Island. The temporal amplitude of EOF mode 1 shows positive peaks in 1994 and 1999 during the second half of the year. This period corresponds to the La Nina events. Similarly the negative peaks in 93, 97, 02, and 03 also coincide with ENSO signals. The EOF mode 1 shows maximum variability in EKE during the La Nina event.

The EOF mode 2 captures $15 \%$ of variability and the spatial structure of this mode also exhibits maximum changes east of Vietnam between $10-15^{\circ} \mathrm{N}$ (Fig. 12). Interestingly, two domes of opposing variability (positive and negative) occur in this region. The negative values extend along the western boundary current region southward from the east coast of Hainan Island. Significant variability is also found in Taiwan Strait. The temporal amplitude exhibits slight seasonal variations and some periodic oscillations modulated by climatic events. Abnormal low values were observed from 1995 and 1998 and high amplitude in 1994 and 1997 and the amplitude showed weak variations from 2005 - 2008.

\section{CONCLUSIONS}

This study illustrated the mean, seasonal and

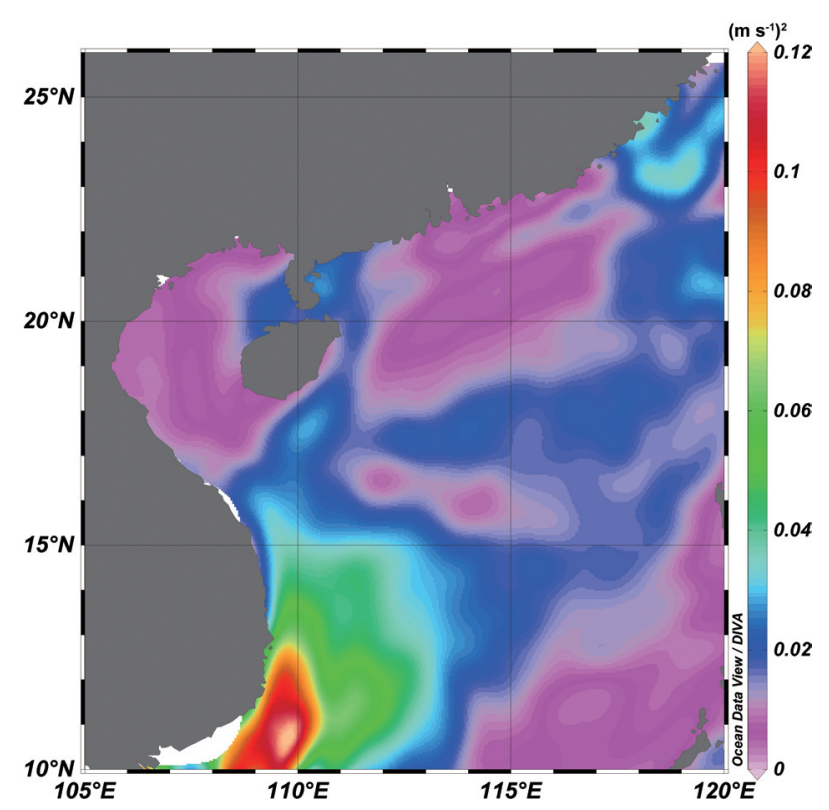

Fig. 9. Distribution of Eddy Kinetic Energy (EKE) $\left(\mathrm{m} \mathrm{s}^{-1}\right)^{2}$.

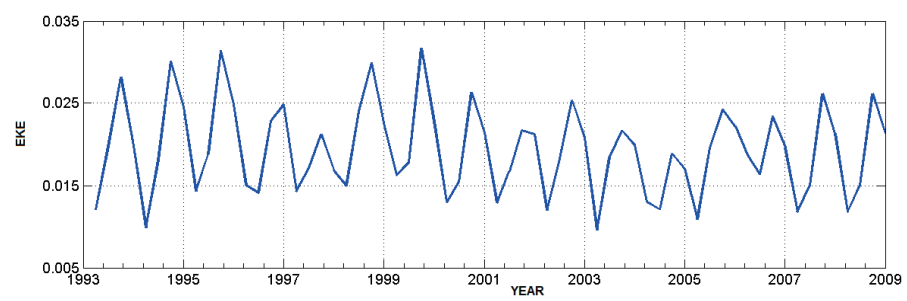

Fig. 10. Annual trend of $\operatorname{EKE~}\left(\mathrm{m} \mathrm{s}^{-1}\right)^{2}$. 


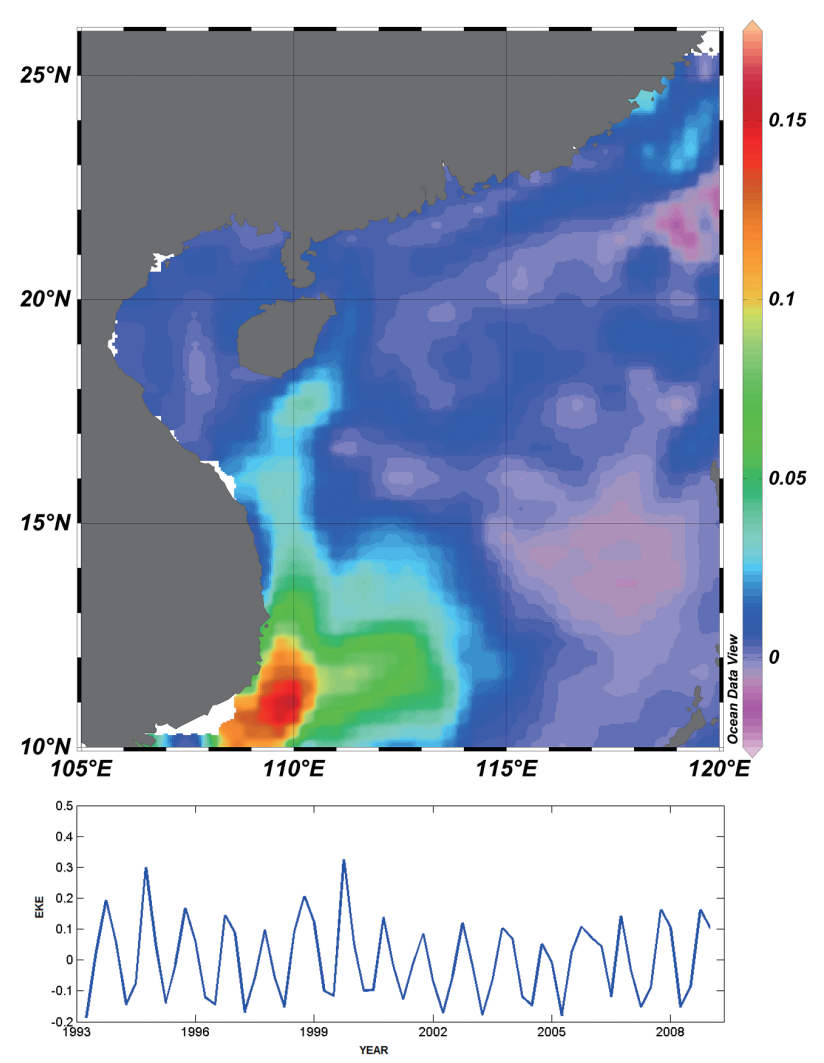

Fig. 11. Spatial structure and temporal amplitudes of EOF mode 1.

inter-annual circulation features of NSCS combining satellite altimeter and the available surface drifter observations. The NSCS displays monsoon circulation with strong boundary currents. The mean velocity field is more aligned to the northeast monsoon circulation pattern. The anomaly field illustrates significant current deviations in the southern part with maximum variability occurring southwest off of Vietnam. The western boundary current and the zonal flow exhibit strong seasonal variations. The Kuroshio intrusion is found throughout the year with slight seasonal variations. The ENSO influence on NSCS circulation is found in zonal and boundary flows. During an El Niño event the western boundary current is weakened in the SCS whereas, the Kuroshio Current is strengthened in the western Pacific. Opposite changes occur in boundary currents during $\mathrm{La}$ Nina periods when the Kuroshio Current is slightly weakened and the western boundary flow is strengthened in the NSCS. The maximum EKE is observed east of Vietnam in the NSCS. In addition to seasonal variations, the EKE distribution is influenced by climate modes. The minimum EKE variability occurs during El Niño and the maximum EKE range occurs during La Nina periods.

Acknowledgements The first author acknowledges financial support for this work from the UTM GUP research grant Vote no. 07J50, MOHE. We used the altimeter data

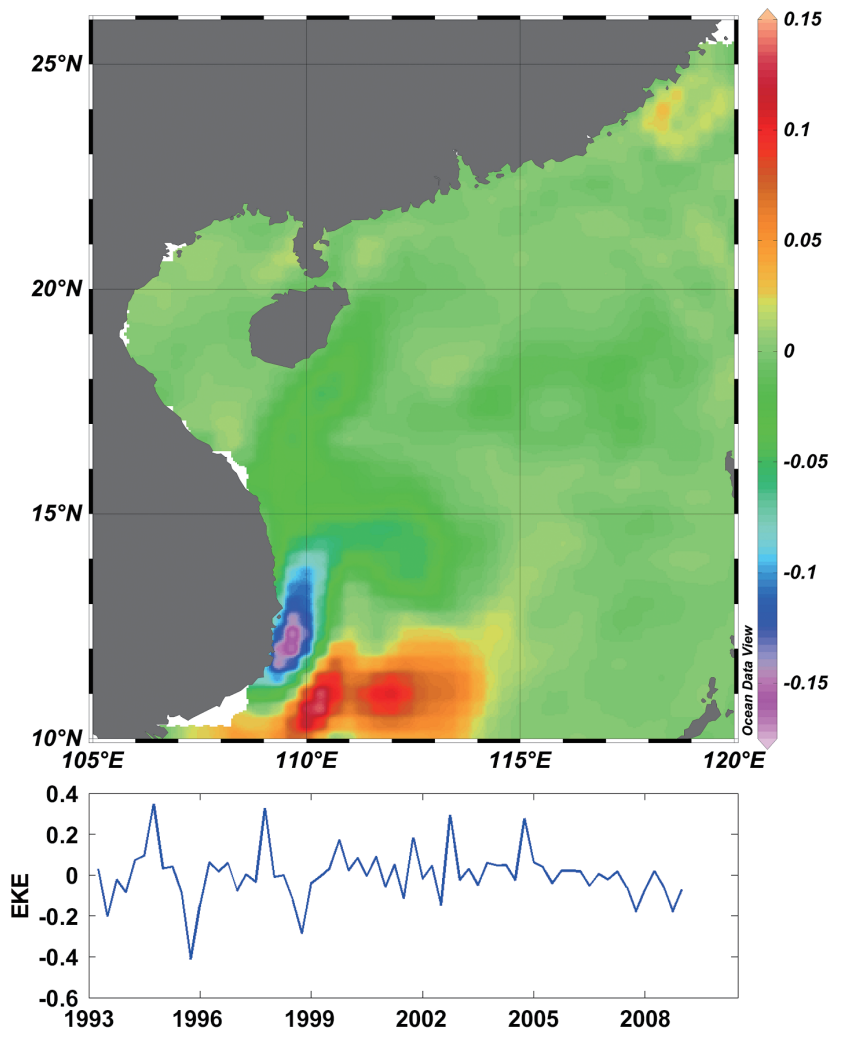

Fig. 12. Spatial structure and temporal amplitudes of EOF mode 2.

set produced by the Collect Localization Satellites, Space Oceanography Division as part of Environment and Climate. Drifter data produced by the National Oceanic and Atmospheric Administration, Atlantic Oceanographic and Meteorological Laboratory are utilized. We also employed the wind data set produced and provided by the French Processing and Archiving Facility (CERSAT) at the French Research Institute for Exploration of the Sea. We used ODV, Schlitzer, R., Ocean Data View, http://odv.awi.de/, 2013, for preparing graphics.

\section{REFERENCES}

Cai, S., J. Su, Z. Gan, and Q. Liu, 2002: The numerical study of the South China Sea upper circulation characteristics and its dynamic mechanism, in winter. Cont. Shelf Res., 22, 2247-2264, doi: 10.1016/S0278-4343(02)00073-0. [Link]

Chao, S. Y., P. T. Shaw, and S. Y. Wu, 1996: El Niño modulation of the South China Sea circulation. Prog. Oceanogr., 38, 51-93, doi: 10.1016/S0079-6611(96)00010-9 . [Link]

Chu, P. C., Y. Chen, and S. Lu, 1998: Wind-driven South China Sea deep basin warm-core/cool-core eddies. $J$. Oceanogr., 54, 347-360, doi: 10.1007/BF02742619. [Link] 
Chu, T. Y., 1972: A study on the water exchange between Pacific Ocean and the South China Sea. Acta Oceanogr. Taiwan., 2, 11-24.

Dale, W., 1956: Wind and drift current in the South China Sea. Malays. J. Trop. Geogr., 8, 1-31.

Fang, G., B. Zhao, and Y. Zhu, 1991: Water volume transport through the Taiwan Strait and the continental skelf of the East China Sea measured with current meters. Elsevier Oceanogr. Ser., 54, 345-358, doi: 10.1016/ S0422-9894(08)70107-7. [Link]

Fang, G., G. Wang, Y. Fang, and W. Fang, 2012: A review on the South China Sea western boundary current. Acta Oceanol. Sin ., 31, 1-10, doi: 10.1007/s13131-012-0231-y. [Link]

Gao, S., H. Wang, G. Liu, and H. Li, 2013: Spatio-temporal variability of chlorophyll a and its responses to sea surface temperature, winds and height anomaly in the western South China Sea. Acta Oceanol. Sin., 32, 4858, doi: 10.1007/s13131-013-0266-8. [Link]

Guan, B. X., 1978: The warm current in the South China Sea. Oceanol.Limnol. Sin., 9, 159-187.

Guo, J., W. Fang, G. Fang, and H. Chen, 2006: Variability of surface circulation in the South China Sea from satellite altimeter data. Chin. Sci. Bull., 51, 1-8, doi: 10.1007/s11434-006-9001-6. [Link]

Ho, C. R., Q. Zheng, Y. S. Soong, N. J. Kuo, and J. H. Hu, 2000: Seasonal variability of sea surface height in the South China Sea observed with TOPEX/Poseidon altimeter data. J. Geophys. Res., 105, 13981-13990, doi: 10.1029/2000JC900001. [Link]

Ho, C. R., Q. Zheng, N. J. Kuo, C. H. Tsai, and N. E. Huang, 2004: Observation of the Kuroshio intrusion region in the South China Sea from AVHRR data. Int. J. Remote Sens., 25, 4583-4591, doi: 10.1080/0143116042000192376. [Link]

Hu, J., J. Pan, X. Guo, and Q. Zheng, 2011: Introduction to the special section on regional environmental oceanography in the South China Sea and its adjacent areas (REO-SCS). J. Oceanogr., 67, 359-363.

Hwang, C. and S. A. Chen, 2000: Circulations and eddies over the South China Sea derived from TOPEX/Poseidon altimetry. J. Geophys. Res., 105, 23943-23965, doi: 10.1029/2000JC900092. [Link]

Jiang, Y., F. Chai, Z. Wan, X. Zhang, and H. Hong, 2011: Characteristics and mechanisms of the upwelling in the southern Taiwan Strait: A three-dimensional numerical model study. J. Oceanogr., 67, 699-708, doi: 10.1007/ s10872-011-0080-x. [Link]

Kuo, N. J., Q. Zheng, and C. R. Ho, 2000: Satellite observation of upwelling along the western coast of the South China Sea. Remote Sens. Environ., 74, 463-470, doi: 10.1016/S0034-4257(00)00138-3. [Link]

Li, L., W. D. Nowlin, and J. Su, 1998: Anticyclonic rings from the Kuroshio in the South China Sea. Deep-Sea
Res. Part I-Oceanogr. Res. Pap., 45, 1469-1482, doi: 10.1016/S0967-0637(98)00026-0. [Link]

Liu, X. and J. Su, 1992: A reduced gravity model of the circulation in the south China Sea. Oceanol. Limnol. Sin., 23, 167-174.

Liu, Z., J. Xu, L. Li, and M. Shi, 2001a: Characteristics and distribution of water masses in the South China Sea during summer and winter of 1998. Oceanogr. China, 13, 221-230.

Liu, Z., H. Yang, and Q. Liu, 2001b: Regional dynamics of seasonal variability in the South China Sea. J. Phys. Oceanogr., 31, 272-284, doi: 10.1175/1520-0485(2001)031<0272:RDOSVI>2.0.CO;2. [Link]

Metzger, E. J. and H. E. Hurlburt, 1996: Coupled dynamics of the South China Sea, the Sulu Sea, and the Pacific Ocean. J. Geophys. Res., 101, 12331-12352, doi: 10.1029/95JC03861. [Link]

Niiler, P. P. and J. D. Paduan, 1995: Wind-driven motions in the northeast Pacific as measured by Lagrangian drifters. J. Phys. Oceanogr., 25, 2819-2830, doi: 10. 1175/1520-0485(1995)025<2819:WDMITN>2.0.CO; 2. [Link]

Nitani, H., 1972: Beginning of the Kuroshio. In: Stommel, H. and K. Yoshida (Eds.), Kuroshio: Physical Aspects of the Japan Current, University of Washington Press, 129-163.

Pazan, S. E. and P. P. Niiler, 2001: Recovery of near-surface velocity from undrogued drifters. J. Atmos. Ocean. Technol., 18, 476-489, doi: 10.1175/1520-0426(2001 )018<0476:RONSVF>2.0.CO;2. [Link]

Pichevin, T. and D. Nof, 1997: The momentum imbalance paradox. Tellus A, 49, 298-319, doi: 10.1034/j.16000870.1997.t01-1-00009.x. [Link]

Qu, T., 2000: Upper-layer circulation in the South China Sea. J.Phys. Oceanogr., 30, 1450-1460, doi: 10.1175/15200485(2000)030<1450:ULCITS>2.0.CO;2. [Link]

Qu, T., H. Mitsudera, and T. Yamagata, 2000: Intrusion of the North Pacific waters into the South China Sea. J. Geophys. Res., 105, 6415-6424, doi: 10.1029/1999JC900323. [Link]

Qu, T., Y. Du, G. Meyers, A. Ishida, and D. Wang, 2005: Connecting the tropical Pacific with Indian Ocean through South China Sea. Geophys. Res. Lett., 32, L24609, doi: 10.1029/2005GL024698. [Link]

Ralph, A. E. and P. P. Niiler, 1999: Wind-driven currents in the tropical Pacific. J. Phys. Oceanogr., 29, 2121-2129, doi: 10.1175/1520-0485(1999)029<2121:WDCITT>2.0.CO;2. [Link]

SCSIO (South China Sea Institute of Oceanology, Academia Sinica), 1985: Report of the 1979-1982 Multidisciplinary Research Program of Northern South China Sea, Vol. II, China Science Press, Beijing, 432 pp. (in Chinese)

Shaw, P. T. and S. Y. Chao, 1994: Surface circulation in 
the South China Sea. Deep-Sea Res. Part I-Oceanogr. Res. Pap., 41, 1663-1683, doi: 10.1016/09670637(94)90067-1. [Link]

Su, J., 1998: Circulation dynamics of the China Seas: North of $18^{\circ}$ N. In: Robinson, A. R. and K. H. Brink (Eds.), The Sea, The Global Coastal Ocean: Regional Studies and Syntheses, Vol. 11, John Wiley, New York, 483-505.

Su, J., 2004: Overview of the South China Sea circulation and its influence on the coastal physical oceanography outside the Pearl River Estuary. Cont. Shelf Res., 24, 1745-1760, doi: 10.1016/j.csr.2004.06.005. [Link]

Uchida, H. and S. Imawaki, 2003: Eulerian mean surface velocity field derived by combining drifter and satellite altimeter data. Geophys. Res. Lett., 30, doi: 10.1029/2002GL016445. [Link]

Wang, C., R. H. Weisberg, and J. I. Virmani, 1999: Western Pacific interannual variability associated with the El Niño-Southern Oscillation. J. Geophys. Res., 104, 5131-5149, doi: 10.1029/1998JC900090. [Link]

Wang, C., W. Wang, D. Wang, and Q. Wang, 2006: Interannual variability of the South China Sea associated with El Niño. J. Geophys. Res., 111, C03023, doi: 10.1029/2005JC003333. [Link]

Wang, D., W. Wang, P. Shi, P. Guo, and Z. Gan, 2003: Establishment and adjustment of monsoon-driven circulation in the South China Sea. Sci. China Ser. D, 46, 173-181.

Wang, J. and C. S. Chern, 1997: On the trajectory of subsur- face and intermediate waters in the northeastern South China Sea. Trop. Oceanol., 16, 24-41.

Wang, L., C. J. Koblinsky, and S. Howden, 2000: Mesoscale variability in the South China Sea from the TOPEX/ Poseidon altimetry data. Deep-Sea Res. Part I-Oceanogr. Res. Pap., 47, 681-708, doi: 10.1016/S0967-0637(99)00068-0. [Link]

Wu, C. R., P. T. Shaw, and S. Y. Chao, 1998: Seasonal and interannual variations in the velocity field of the South China Sea. J. Oceanogr., 54, 361-372, doi: 10.1007/ BF02742620. [Link]

Wyrtki, K., 1961: Physical oceanography of the Southeast Asian waters. NAGA Report, Vol. 2, Scientific Results of Marine Investigations of the South China Sea and the Gulf of Thailand 1959-1961, The University of California, Scripps Institution of Oceanography, La Jolla, California, 195 pp.

Xu, J. P., J. L. Su, and D. Z. Qiu, 1996: Hydrographic analysis on the intrusion of Kuroshio water into the South China Sea. Oceanogr. China, 6, 1-12.

Xu, X., Z. Qiu, and H. Chen, 1982: The general description of the horizontal circulation in the South China Sea. Proceedings of the Marine Hydrographic and Meteorology Society of China, Science Press, Beijing, 137-145.

Yuan, D., W. Han, and D. Hu, 2006: Surface Kuroshio path in the Luzon Strait area derived from satellite remote sensing data. J. Geophys. Res., 111, C11007, doi: 10.1029/2005JC003412. [Link] 